\title{
Protecting the neonatal brain: Finding, treating, and preventing seizures
}

\author{
Carl L. Backer, MD, ${ }^{a}$ and Bradley S. Marino, MD, MPP, MSCE ${ }^{b}$
}

See related article on pages $169-80$.

The American Clinical Neurophysiology Society has certainly drawn an interesting line in the sand. That organization has set forth a consensus statement recommending consideration of continuous electroencephalographic monitoring (EEG) after neonatal cardiac surgery. We laud Naim and colleagues ${ }^{1}$ from the Children's Hospital of Philadelphia, who have put this mandate to the test and given us some very important results in this issue of the Journal. The Children's Hospital of Philadelphia group studied 161 neonates with routine continuous EEG monitoring after open heart surgery. In the postoperative period, $8 \%$ of the infants had seizure activity, which was only demonstrated by the use of EEG in $85 \%$ of those babies. The neonates who had seizures had a high mortality of $38 \%$, versus only $3 \%$ for patients who did not have seizures. It is also well known that postoperative seizures are associated with worse neurodevelopmental outcomes, ${ }^{2}$ and there is evidence suggesting that early and effective treatment of seizures will improve neurodevelopmental outcomes. ${ }^{3}$ In their article, Naim and colleagues ${ }^{1}$ have clearly pointed out that if we don't carefully assess for seizure activity with EEG monitoring, we will not identify these at-risk neonates. These findings are very important for several reasons.

First, it is clearly no longer adequate for investigators reporting outcomes after neonatal cardiac surgery to state that neonates did not have postoperative neurologic complications if they do not use continuous EEG monitoring. Of the neonates in this series, $85 \%$ had seizures documented only by EEG; there were no clinical signs. Reliance on postoperative physical examination is not adequate to rule out postoperative neurologic complications.

Second, Naim and colleagues ${ }^{1}$ are also to be congratulated for their advanced neurologic critical care department

From the ${ }^{a}$ Division of Cardiovascular-Thoracic Surgery, Ann \& Robert H. Lurie Children's Hospital of Chicago, Chicago, Ill; and the ${ }^{\mathrm{b}}$ Division of Cardiology, Ann \& Robert H. Lurie Children's Hospital of Chicago, Chicago, Ill.

Disclosures: Authors have nothing to disclose with regard to commercial support.

Received for publication April 10, 2015; accepted for publication April 13, 2015; available ahead of print May 13, 2015.

Address for reprints: Carl L. Backer, MD, Division of Cardiovascular-Thoracic Surgery, Ann \& Robert H. Lurie Children's Hospital of Chicago, 225 E Chicago Ave, mc 22, Chicago, IL 60611 (E-mail: cbacker@luriechildrens.org).

J Thorac Cardiovasc Surg 2015;150:6-7

$0022-5223 / \$ 36.00$

Copyright (C) 2015 by The American Association for Thoracic Surgery

http://dx.doi.org/10.1016/j.jtcvs.2015.04.028 with the availability of EEG technologists 24/7. In addition, all patients had comprehensive 12-scalp electrode monitoring. This level of sophisticated monitoring, of

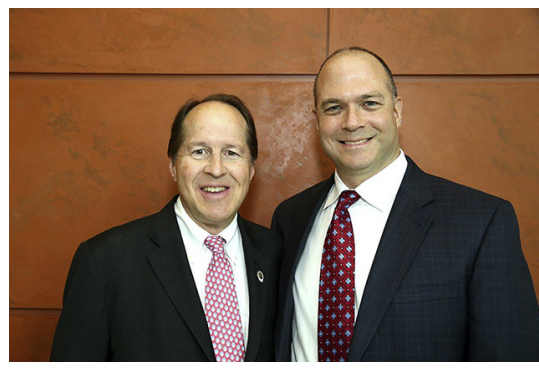
course, is not available at all institutions. What we need is a screening tool that is not as labor intensive, both from a staffing standpoint (24/7 EEG technologists) and the required precise application of so many scalp electrodes. Much as the use of regional oxygen saturation monitors as a screening tool has improved postoperative outcomes in the pediatric cardiac care unit, a screening continuous EEG monitor would allow us to identify more easily these infants with a minimum of expense. If the screening identifies seizure activity, the child could then have placement of the full EEG for evaluation of treatment. This would remove the expense and staffing associated with full EEG monitoring for the $92 \%$ of patients who did not have seizures.

Third, another important finding in this study was that if the patients had seizures, they had a distinctly increased mortality. ${ }^{1}$ Although this may have been a result of increased severity of disease and comorbidities, the prevention of postoperative seizures is still an important goal. Of course, that goal can only be achieved if we monitor for seizures and then use assessment of various surgical and postoperative management strategies to eliminate the development of seizures. We must, however, first find seizures to know how to prevent and treat them. Their prevention is critically important.

All of these points lead us to believe that what is really needed is a multicenter observational cross-sectional study with continuous EEG monitoring. This high-risk population deserves that type of careful analysis with more than just the number of patients available at a single institution to help us determine strategies that will prevent seizures and then, if they occur, find the best strategies for treating them. This will have the important result of improving the neurodevelopmental outcomes of infants undergoing neonatal heart surgery.

\section{References}

1. Naim MY, Gaynor JW, Chen J, Nicolson SC, Fuller S, Spray TL, et al. Subclinical seizures identified by postoperative electroencephalographic monitoring are 
common following neonatal cardiac surgery. J Thorac Cardiovasc Surg. 2015; 150:169-80.

2. Bellinger DC, Wypij D, Rivkin MJ, DeMaso DR, Robertson RL Jr, DunbarMasterson C, et al. Adolescents with d-transposition of the great arteries corrected with the arterial switch procedure: neuropsychological assessment and structural brain imaging. Circulation. 2011;124:1361-9.
3. Marino BS, Lipkin PH, Newburger JW, Peacock G, Gerdes M, Gaynor JW, et al; American Heart Association Congenital Heart Defects Committee, Council on Cardiovascular Disease in the Young, Council on Cardiovascular Nursing, Stroke Council. Neurodevelopmental outcomes in children with congenital heart disease: evaluation and management: a scientific statement from the American Heart Association. Circulation. 2012;126:1143-72.

Access to The Journal of Thoracic and Cardiovascular Surgery Online is reserved for print subscribers!

Full-text access to The Journal of Thoracic and Cardiovascular Surgery Online is available for all print subscribers. To activate your individual online subscription, please visit The Journal of Thoracic and Cardiovascular Surgery Online, point your browser to http://www.mosby.com/itcvs, follow the prompts to activate your online access, and follow the instructions. To activate your account, you will need your subscriber account number, which you can find on your mailing label (note: the number of digits in your subscriber account number varies from 6 to 10 ). See the example below in which the subscriber account number has been circled:

\section{Sample mailing label}

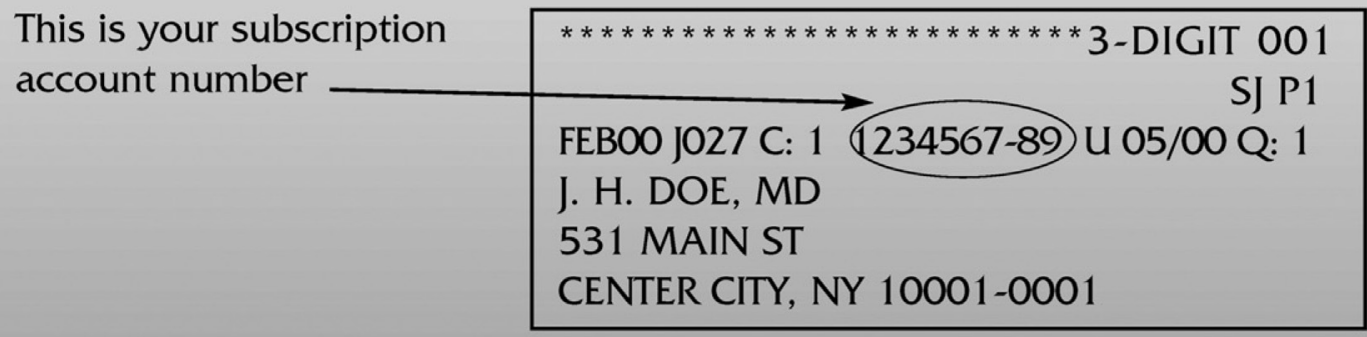

Personal subscriptions to The Journal of Thoracic and Cardiovascular Surgery Online are for individual use only and may not be transferred. Use of The Journal of Thoracic and Cardiovascular Surgery Online is subject to agreement to the terms and conditions as indicated online. 